\title{
Enhancing Oneness through a Co-Housing Community
}

Nandana Madathil Thankamoniyan ${ }^{\dagger}$ and Dr. Sharmila Jagadisan ${ }^{\sharp}$

\section{Abstract}

Many of us live in conventional housing facilities, and recent changes in the demographic shift and economic changes create a more significant impact and reshape the spaces we live, work, etc. Modern life makes it challenging to find an answer for the housing crisis and social change, and this, when paired with a safety and security crisis, we can see the decline in meaningful social connections, isolation, leading to sparse human interactions and a lack of vibrant community life. These issues, in turn, threaten not just the quality of life but also human well-being. In response, architecture must create an inclusive urban fabric that meets all groups of people's social, physical and economic needs. One way to deal with these issues is by revisiting previous models of inhabitation, analysing and modifying them in order to achieve a sustainable living model. This study aims to understand and compare the existing models of co-housing communities across the globe and provide insights into how the concept of co-housing is evolving and how it is likely to impact India. A survey has been conducted with 150 people of diverse age groups to understand the needs and trends of people and further by developing a framework for co-housing communities in an urban setting, where it has the potential to offer a different scale of social organisation and to provide a supportive housing environment emphasising more on sustainable lifestyle practices. Architecture must enhance a person's lifestyle, and co-housing can catalyse the same.

Keywords: Privacy; Co-housing; Integration; Shared Spaces; Collaboration; India

\footnotetext{
${ }^{\dagger}$ B.Arch Final Year Student, School of Architecture, VIT (Vellore Institute of Technology) Email:nandana.madathil2016@vitstudent.ac.in

¥ Corresponding Author, Associate Professor, School of Architecture, VIT (Vellore Institute of Technology), Vellore 632014

Email: sharmila.jagadisan@vit.ac.in

(C) 2021 Thankamoniyan\&Jagadisan. This is an Open Access article distributed under the terms of the Creative Commons Attribution License (http://creativecommons.org/licenses/by/2.0), which permits unrestricted use, distribution, and reproduction in any medium, provided the original work is properly cited.
} 


\section{Introduction}

Co-housing is an approach to creating a neighbourhood that embodies particular values. It also refers to a bunch of individuals who intentionally gathers to create, build and board a community; this empowers them to measure their way and improve their lifestyle and well-being (Scotthanson and Scotthanson, 2005). The design of a co-housing community encourages both individual space and social connections. This study aims to understand and compare the existing models of co-housing communities across the globe and provide some insights into how the concept of co-housing is evolving and how it is likely to create an impact in the near future in India. The objectives of this study are as follows:

- To analyse and evaluate the existing models of co-housing communities, which exist both at the national and international level.

- To compare and critically analyse case studies of co-housing models in European and Asian continents along with India.

- To create an overview of why co-housing communities will become necessary and impact India's near future.

- To create a framework for co-housing facilities which could be developed in the future on Indian standards.

It remains well documented that housing is widely recognised as a social determinant of health. Some research evidence shows that the communal living arrangements reduce feelings of loneliness and increase perceived well-being among the residents. The existing literature on co-housing is characterised by a certain degree of ambiguity and overlap between different terms and experiences (Carrere et al., 2020). This concept has already been popular in Europe and the US, including some Asian countries like Hong Kong and China (Sundar, 2018). With respect to India, co-housing is still in the nascent stage, and many are not clear about how it can work in the Indian context. In recent time, we can see that an informal concept of renting and sharing 3 to 4 bedroom house prevails in metro cities. But taking this on a larger scale needs to be analysed. To have a basic understanding, the authors have circulated the survey to 150 people of the age group 21-70. The questions were posed to create a holistic understanding of a Co-housing community where they would like to live if they had an opportunity to. The questionnaire has been formed based on six principles, which were derived from the parameters used for the case study comparison. The methods of the study are outlined below.

\section{Methods of the Study}

To analyse and evaluate the existing models of co-housing communities, which exist both at the national and international level, the following study has been undertaken as a descriptive analysis with the help of case studies chosen from abroad and India. These case studies have been further compared on the basis of the following parameters :

- Users and Governance

- Privacy and connectedness

- Design layout and construction

- Culture and economy

- Sustainable Practices

From these comparisons, the effectiveness and gaps of existing co-housing models have been identified. In addition, primary research was conducted through a structured questionnaire circulated online to get opinions regarding cohousing in India. A Google survey has been circulated across a diverse age group of 21 - 70, comprising of working bachelors, family, retired seniors, seniors with assisted living (not geriatric patients), recording responses of 150 people in India. Based on the analysis, recommendations were made for a future co-housing facility which sets the conclusion for this research. Figure 1 illustrates the structure of the study. This is followed by a review of the literature. 


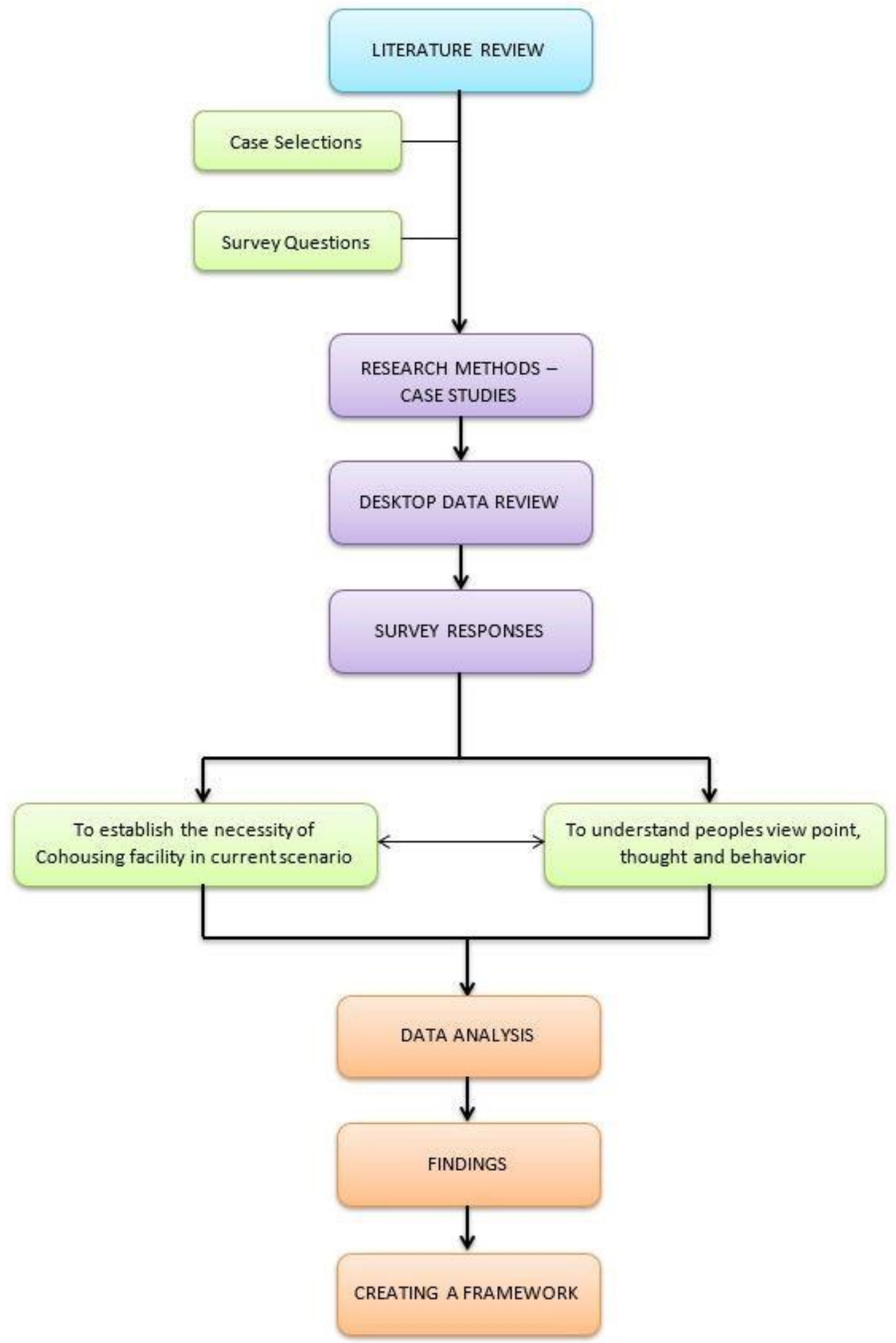

Figure 1: Methodology of the Study Source: Authors 


\section{Review of Literature}

Envisage living in a vibrant community which is environmentally aware, energy efficient. With willing, fun loving, diverse people sharing the many household tasks across the community, creating more free time to live your dreams, and reducing your cost of living! Home grown veggies! - Bridges (Holtzman Gilo, 2010, p.7).

\section{What is Co-housing?}

Co-housing is the short form of collaborative housing, a type of intentional community that includes Student Coops, Communes, EcoVillages and Community Land Trust. It is a living environment where doors do not have to be locked, where significant relationships with neighbours are the norm and where generations mix and everybody has a role (Holtzman, 2010.). Along with a traditional private home facility, residents have access to extensive common amenities like open space, courtyard, and common house. Shared spaces could also include parking, walkways, open space etc (Kim Grace, 2012). These communities revolve mainly around three principles which make them unique from conventional neighbourhoods (Meyer, 2018):

- Emphasis on the growth of the community

- Increasing Sustainability

- Ageing successfully

\section{History of Co-housing}

Around 2,400 years ago, the Greek philosopher Plato delineated a perfect community where everything was organised collectively. In 1506, the Englishman Thomas More1 published the book 'Utopia', which means no place, gave a reputation to such visions. In Mores' ideal community, people lived in neighbourhood groups with common dining areas and various other shared leisure facilities. His description

1 Thomas More (1478-1535), also called Saint Thomas More, was an English lawyer, social philosopher, author, and statesman. Utopia 1516, his most well-known and controversial work, a novel in Latin. In it he describes the of a perfect community was the simplest way to criticise the present society.

Co-housing initially took roots in Denmark in the middle of the 1960s, nearly at the same time in Scandinavian nations like Sweden and European countries like Holland where it Copenhagen. It housed twentyseven families drawing influence from Bodil Graae's 1967 article, “Every kid ought to have a hundred parents". Even today, close to $1 \%$ of the Danish population still live in co-housing communities, totalling around 50,000 people. The collaborative design has evolved over time through a good amount of trial-anderror, currently favouring smaller

individual spaces with larger common areas (Scotthanson and Scotthanson, 2005).

The term, 'co-housing', translated from the Danish word 'bofaellskaber' meaning 'living together, was first introduced in 1989 in the book by McCamant et al. (1989) titled Cohousing: A Contemporary Approach to Housing Ourselves. In the co-housing model, the community residents own or rent their homes and also have a share in the communal space and the common house, where community activities occur. Although community participation is encouraged, the extent of the involvement in their community is entirely voluntary.

\section{Why Co-housing? Why now?}

No man is an island, entire of itself; every man is a piece of the Continent, a part of the main - John Donne (English Poet, 1624)

Whether in the public realm, workspace or housing, shared living has been of long interest to us. As a society, we have mostly moved away from joint families 2 and shared living to individual houses. Housing shortages, inflating prices, and increased levels of loneliness, mainly in cities, show that shared living is becoming

political arrangements of the imaginary island country of Utopia.

2 Joint families are composed of sets of siblings, theirs spouses, and their dependent children (Little and McGivern, 2012) . 
increasingly relevant and that dense and sustainable living idea are necessary (Crerar, 2017).

Co-housing also develops relationships, shared values and participation. The neighbours will be a part of a community for the mutual benefit of all. It helps in cultivating a culture of caring and sharing. The design type and community size promote frequent interactions leading to close relations (The Guardian, 2019). Though with all the shared level of community interactions, cohousing also offers a healthy balance of privacy, and individuals can choose their own level of engagement. Residents have independent incomes and personal lives, but the neighbourhood collectively plans and manages community activities. These activities feature scheduled shared meals, meetings and workdays regularly. The residents gather for games, parties, functions, movies and other events (White and Loper, 2015). Co-housing also makes it easier to form clubs, organise child and elder care.

The need for a co-housing can be summarised as the following (Mary, n.d. ):

- Save time and money

- Flexibility and support with child care and elderly

- Better safety and security

- Shared amenities

- True neighbourliness

\section{Sharing the Future through Co-housing}

Co-housing is a way of combating the alienation and isolation which many experiences today. Cohousing communities are designed and ruled by and for the individuals living in them, so all these communities are uniquely tailored to their individual community. The main benefit of cohousing is that it enjoys the sense of a community. They are meticulously designed to increase and encourage social interactions. This is achieved through the physical layout and established bylaws (McCamant et al., 1989).

Even though each family has a private home, typically smaller than a conventional house, the community shares a huge common house. This common house usually comprises a large kitchen, dining rooms for optional meals, which occur one to four times a week, gym, play area, laundry and guest rooms. This common space helps the residents to socialise. Most of the residents love the idea of shared meals as this paves the way to lesser cooking and more variety when compared to living in a conventional home (McCamant et al., 1989).

The bye-laws decided by the community ensure a strong sense of belonging. Many intentional communities have failed due to improper planning of laws, but the co-housing community is free of this issue as the laws are made through a long process where several interested individuals gather and develop the rules and expectations. The bylaws are formed from these rules, which every community member adhere to or may face fines. These rules could also include work details, like every member above the age of 18 must put in 20 hours of work for the community every month. The development of these rules takes several years and is often revised annually with mutual consensus. Even though the process may take several years, it also helps in self-selecting future residents. Those who are unwilling to abide by the rules will most likely leave the place, leaving only those truly interested.

Consensual planning gives individuals the flexibility to choose where they live. As a result, many clusters choose to live in cities as more individuals prefer to live close to shops and work. This is helpful for future residents and is also more environmentally friendly as it reduces the use of cars and promotes walking (Jarvis, 2011).

The opportunity to socialise helps not only the adults but also the children. They often find other children to play with within the community, so the parents do not have to drive them to a friend's house. Children living in cohousing tend to be better at making more friends as they associate with non-family members of various age groups, including adults daily, way more than average children (Prentice \& Scutella, 2019). These children will also have more independence as their parents will know all their neighbours well, which calls for 
minimum supervision while playing outside in the community.

Certain segments of our society can benefit more from co-housing communities. Namely, single parents. It becomes effortless to find a babysitter, and the parents might have more free time to relax, complete chores and social life. Likewise, senior citizens benefit by having people who will help them with tasks. As per data, many elderlies prefer co-housing to assisted living as they can be more expensive comparatively, and they also have less independence and autonomy (Cummings \& Kropf, 2019). The key aim of this study is to enhance the co-housing community. The following section indicates the indicators of selecting co-housing case studies from different parts of the world and Asia. Comparison between international and Indian Co-housing are presented after that.

\section{Selection of Case Studies}

Cohabitation has become a widespread phenomenon with varying typologies of shared living. The following are the parameters set for selecting the case studies (see, Figure 2 ).

- Typology of project

- The age group of users

- Number of users

- Context of case studies

- Use of space

- Activities within the community

Due to space constraints, the summary of the case studies is presented in Figure 3
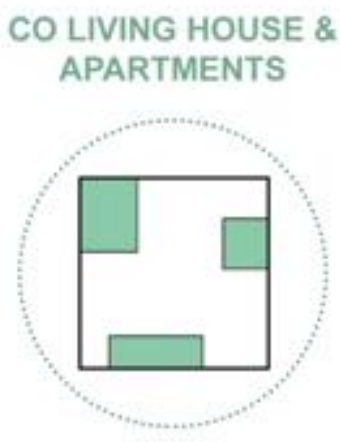

WORLD WIDE

CASE STUDIES

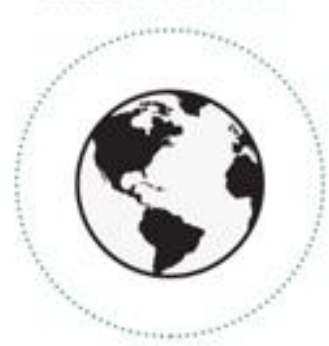

\section{DIVERSE AGE} GROUPS

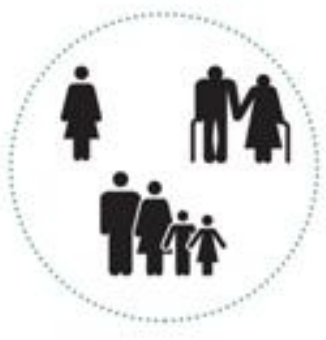

PRIVATE AND

SHARED SPACES

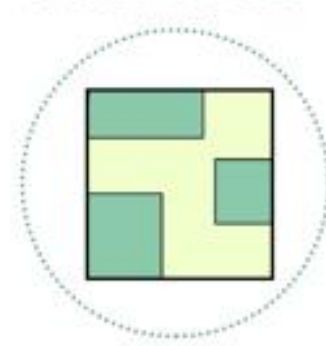

NO. OF

RESIDENTS

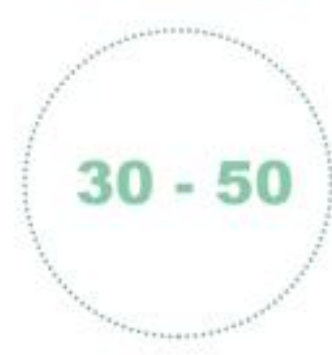

SUSTAINABILITY

PRACTICES

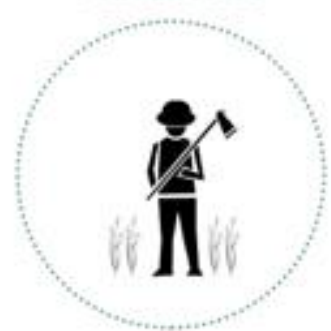

Figure 2: Parameters for selecting the case studies

Source: Authors 


\begin{tabular}{|c|c|c|c|c|}
\hline & & Coop Housine, Berlin & Share House, Jepan & More than Livine, Zurich \\
\hline 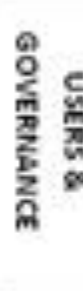 & & $\begin{array}{l}\text { - } 40 \text { residents } \\
\text { - Joint ovnership } \\
\text { GE. Iif }\end{array}$ & $\begin{array}{l}\text { - } 13 \text { regidents } \\
\text { - Singular model } \\
\text { - Uncelated strangers }\end{array}$ & $\begin{array}{l}\text { - } 20 \text { residents } \\
\text { - Cluster apartments } \\
\text { - Unrelated strangers }\end{array}$ \\
\hline 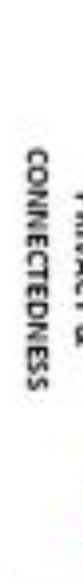 & 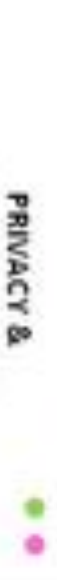 & $\begin{array}{l}\text { - Private: } 26.7 \% \\
\text { - Shased:73.3\% } \\
\text { - dear demarcation } \\
\text { of spaces. }\end{array}$ & $\begin{array}{l}\text { - Private: } 44 \text { to } \\
\text { - Shared : } 56 \% \\
\text { - Kitchen and dining arta are } \\
\text { strong areas of in ter axtion. } \\
\text { - Rooftop is also a shared } \\
\text { space }\end{array}$ & $\begin{array}{l}\text { - Private : } 48.3 \% \\
\text { - Shared : } 51.7 \% \\
\text { - Almost equal division of } \\
\text { - pares. } \\
\text { - Variety of options for } \\
\text { community engagements }\end{array}$ \\
\hline $\begin{array}{l}8 \\
\frac{2}{2} \\
\frac{2}{2} \\
\frac{2}{2} \\
\frac{3}{2}\end{array}$ & $\frac{0}{\frac{0}{6}}$ & $\begin{array}{l}\text { - Modular design } \\
\text { - Low cost }\end{array}$ & $\begin{array}{l}\text { - Single shared block in the } \\
\text { midele with individual } \\
\text { units a ound. }\end{array}$ & $\begin{array}{l}\text { - Guster flats with public } \\
\text { \$aces in between. }\end{array}$ \\
\hline $\begin{array}{l}\frac{m}{8} \\
\frac{8}{2} \\
\frac{2}{2} \\
2\end{array}$ & $\frac{\mathfrak{c}}{\mathrm{C}}$ & $\begin{array}{l}\text { - High Diversity } \\
\text { - Cost elficient }\end{array}$ & $\begin{array}{l}\text { - Worling and studying } \\
\text { bachelors } \\
\text { - Economical } \\
\text { - Located in the urban } \\
\text { center. }\end{array}$ & $\begin{array}{l}\text { - High Diversity } \\
\text { - Economical } \\
\text { - Located in Suburbs } \\
\text { - Well used } \\
\text { common spaces }\end{array}$ \\
\hline 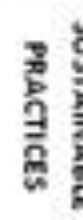 & 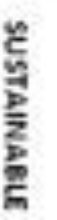 & $\begin{array}{l}\text { - Self-production of } \\
\text { renewable energy }\end{array}$ & NIL & - Communify Garden \\
\hline
\end{tabular}

Figure 3: Summary of International Case Studies Source: Authors 


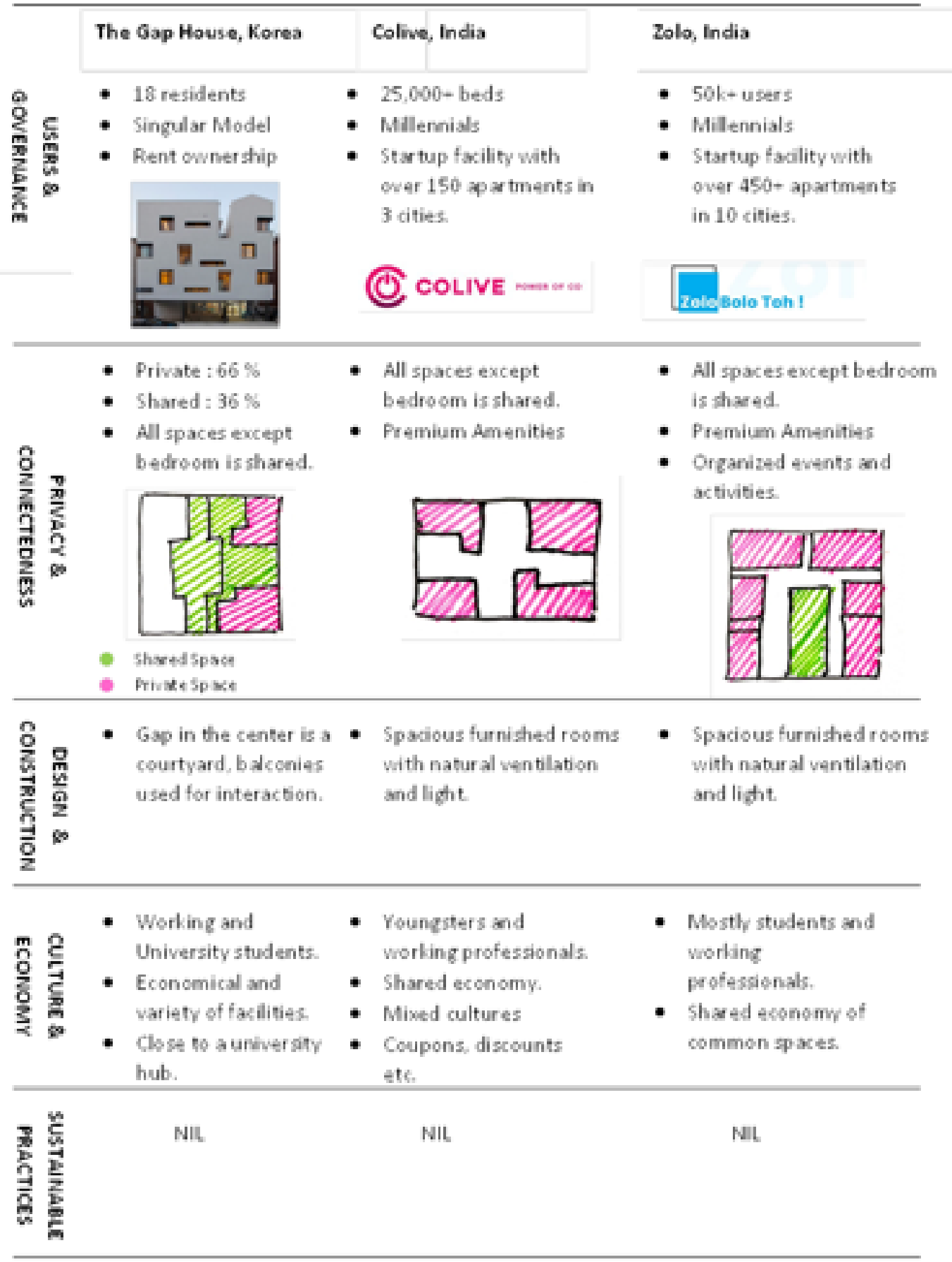

Figure 4: Summary of Asian Case Studies Source: Authors

\section{Comparison between International and Indian Co-housing}

It is clearly evident that the true sense of cohousing communities has not yet been introduced in India and that people are still new to this concept. The merits would mainly include the ease of availability and low cost. These ventures are available in most Indian cities and help in catering for the needs of millennials, for whom the rising price has made it challenging to find an affordable living. This also helps find a solution for the large influx of people coming to urban cities who face dense housing conditions.

Though it has its own merits, the core principle of belonging cannot be achieved through this. People living within would not necessarily know the people in the apartment, as flats can be rented out to anyone. The level of interaction 
and engagement of individuals will differ, and a diversity and near-zero common vision (Figure true sense of co-housing is lost with minimal 5).

\begin{tabular}{|c|c|c|}
\hline 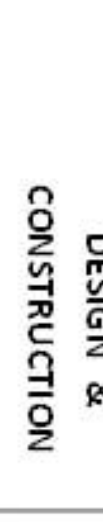 & $\begin{array}{l}\text { International Case Studies } \\
\text { - Varies according to different } \\
\text { communities, catering to the needs } \\
\text { and wishes of the members, put } \\
\text { forth during initial participatory } \\
\text { process. } \\
\text { - Also includes self-construction and } \\
\text { design. }\end{array}$ & $\begin{array}{l}\text { - All units are predesigned with } \\
\text { no involvement from residents. } \\
\text { - Flats within an apartment } \\
\text { mostly have the same design } \\
\text { with minimum variations. }\end{array}$ \\
\hline & $\begin{array}{l}\text { - Mostly high diversity can be } \\
\text { observed in terms of age and } \\
\text { culture. } \\
\text { - Communities decide it in initial } \\
\text { stages so as to bring comfort \& } \\
\text { sense of belonging to every } \\
\text { resident. }\end{array}$ & $\begin{array}{l}\text { - Used by youngsters moving } \\
\text { into new cities for job or } \\
\text { education. } \\
\text { - Diversity in age is not vast. } \\
\text { - No choice on the people you } \\
\text { share the community with, so } \\
\text { less sense of belonging. }\end{array}$ \\
\hline 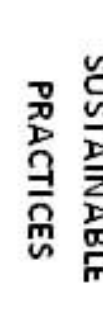 & $\begin{array}{l}\text { - Basic level of sustainability } \\
\text { - Mractices has been incorporated. } \\
\text { - The opportunities for the same } \\
\text { - The residents are a part of these } \\
\text { activities. }\end{array}$ & $\begin{array}{l}\text { - No sustainable practices have } \\
\text { been considered as most of } \\
\text { these flats were pre built and } \\
\text { later converted to cohousing. } \\
\text { - Inclusion should be a must. }\end{array}$ \\
\hline 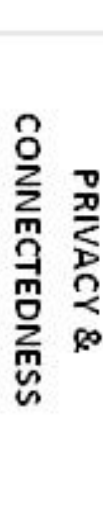 & $\begin{array}{l}\text { - Extreme importance has been } \\
\text { given to spaces and clear } \\
\text { demarcation is present. } \\
\text { - Residents have a sense of } \\
\text { belonging and high interaction } \\
\text { due to these spaces. } \\
\text { - The mixed demography also plays } \\
\text { a part in this. }\end{array}$ & $\begin{array}{l}\text { - Not many shared spaces except } \\
\text { the kitchen which too is like a } \\
\text { restaurant. } \\
\text { - Most residents don't know each } \\
\text { other as community activities } \\
\text { are next to none, residents keep } \\
\text { varying from time to time and } \\
\text { they are mostly involved in } \\
\text { career activities. }\end{array}$ \\
\hline
\end{tabular}

Figure 5: Comparison between International and Indian Case Studies Source: Authors 


\section{Gaps and Effectiveness from Case Studies}

Gaps

\section{Communication and Interaction}

The Co-housing communities understand the importance of neighbourhood interaction, and they try and implement practices and activities that encourage these interactions, but it seldom goes beyond the immediate neighbourhoods.

These communities should be an additional asset to the people living within, not the only asset. Thus, communication within a community network in a city could enhance the lifestyle in terms of engagement and diversity.

\section{Lack of Common Vision towards Sustainability}

Sustainability is a key factor that is being discussed widely but not acted upon as much with the current progress of the world. Incorporating sustainable practices in terms of design, construction, and activities can enhance these communities and set an excellent example for future generations. Only two of them have incorporated sustainable practices from the chosen case studies, that too, on a fundamental scale.

\section{Consumption Challenge}

The continuous need for consumption that we humans are accustomed to hinders the collaborative process and, in many cases, restricts it. Consumption is ingrained into humans that without recognising it as something odd or destructive. These issues also happen in the communities where sharing appliances are restricted because several members have their tools and are not comfortable sharing them.

\section{Diversity and Affordability}

It could be a challenge to maintain a healthy demographic profile in co-housing communities. When these existing communities become older, there will be a necessity for younger members. But on the other hand, the existing older members might prefer to stay and live in their own community, leading to a limited number of available housing units.

Compared to a conventional apartment, the existing co-housing is hard to find and costlier; hence, affordability becomes a critical issue, and the younger population is the most affected by the developed markets.

Most co-housing also acts on a smaller scale which makes it challenging to address diversity issues. This is where interaction and engagement with other communities and city councils could encourage richer diversity and mixed neighbourhoods.

\section{Effectiveness}

\section{Social Benefits}

Co-housing communities help tackle a few of the common challenges that plague our societies; isolation, lack of trust, and depression are a few to name. These communities offer a solution by creating a sense of community that enables interaction, sharing, confidence and general well-being and care. Most of the case study communities have a compassionate understanding and acceptance towards others. This, in fact, is one of the core principles on which these communities perform. Co-housing can address many aspects of human needs 3 as defined by Max-Neef et al. (1991) and can serve good knowledge about the art of communal living.

\section{Decision Making}

These communities have a proper governance system where every member's opinion is taken into consideration. Every individual has equal rights. In conventional apartments, there are association bodies or committees which take decisions. Though these committees are set for the welfare of the residents, more often than not, there is a sense of disagreement between the residents and committees. This tension is avoided in these co-housing communities by not

\footnotetext{
${ }^{3}$ Max-Neef's human needs: identity, protection, subsistence, participation, affection, understanding, leisure, creation, freedom.
} 
having set titles of governance. But every member comes together and makes decisions.

\section{Privacy and Connectedness}

The communities have been able to strike a balance between spatial divisions in terms of shared and private spaces. The idea of social living is appealing to some extent, but it is also extremely important to cater to the needs of the individualism of every member. This has been achieved in the case studies chosen by creating fixed spaces for every activity and has been decided upon by the members themselves.

\section{Principles for the Questionnaire}

After analysing the case studies, the authors decided to conduct a survey to understand the need and trends of co-housing within Indian context and develop a framework. A survey was conducted and circulated to 150 people of the age group 21-70. The questions were posed so as to create a holistic understanding of a Cohousing community where they would like to live if they had an opportunity to. The questionnaire has been formed based on 6 principles, which were derived from the parameters used for the case study comparison.

\section{Participatory Process and Governance}

The participatory process is how all the members are expected to achieve active participation in decision making. This helps in creating productive discussions, which leads to positive solutions that are accepted by all.

In every project, there will be a structure that helps the management. It could be hierarchical or non-hierarchical. Governance helps in setting rules and guides for enforcement. This goes hand in hand with the participatory process, where the people come together and decide upon the governance. There are a variety of ways to achieve this.

Responses from the subjects will help us understand when and to what level the people would like to be involved in decision making regarding the community.

\section{Neighbourhood Design}

This focuses on the design aspects of the community like the surrounding area, shaping the layout, use of streets, buildings, natural spaces and pathways to create connectedness and liveliness in a community. The responses will give an idea about the comfort level of people

\section{Common Facilities}

Common facilities are those areas or amenities that all the members have equal rights to access and use within the community. Different people will have different comfort levels of sharing things, and the responses will help us create a division for these.

\section{Private Individual Spaces}

Though people like the idea of co-housing, when they interact closely within the community, many may find that the experience of living in such a facility can get quite challenging. Individualism is a human need and helps in maintaining a balance in life. Therefore, private spaces are as important as the shared space, and these have to be carefully chosen as per the wishes of the members of the community.

\section{Resident Management (Cultural Outlook)}

As the core principle of a Co-housing community is that the members will be like one big family, it is extremely important that all the members are comfortable with one another. Diversity in terms of age, culture and religion have to be accepted by the members. It is not necessary that everyone should be comfortable with diverse people living nearby. The responses help us in arriving at a pattern that will help us to determine the commonalities.

- you can manage to work with people from a different region

- you prefer to work with the people of the same region.

\section{Survey Responses}

From the 150 people surveyed, 44\% (66 people) are of the age group of $21-29$, followed by $32.7 \%$ (49 people) in 30-49, $14.7 \%$ (22 people) in 50-69 and finally, $9.3 \%$ (14 people) in 70+. Out of the 150 people, $77.3 \%$ (116 people) has already been a part of shared living such as college dorms, housing co-ops etc., and most have rated 
the experience on the Likert scale as neutral to very good (Figure 6).

The majority of the surveyed people include millennials. Most people already have an

Age

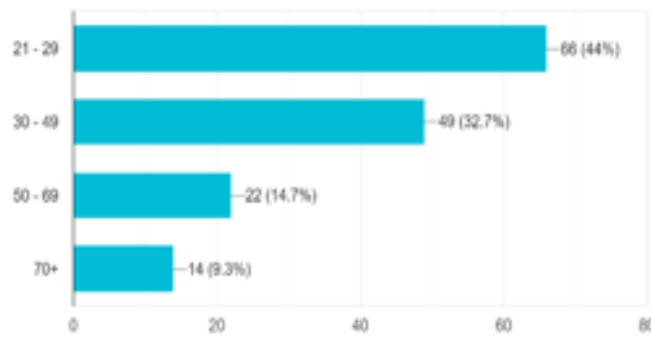

experience of living in shared facilities and have a favourable opinion about the same. The following are the observations from the survey using regression analysis; first, though, the profile of the respondents are outlined below:

Have you lived in shared or cooperative ling shuations before, such as shared group households. student housing co-ops, or colege dorms?
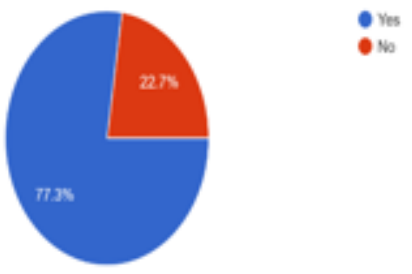

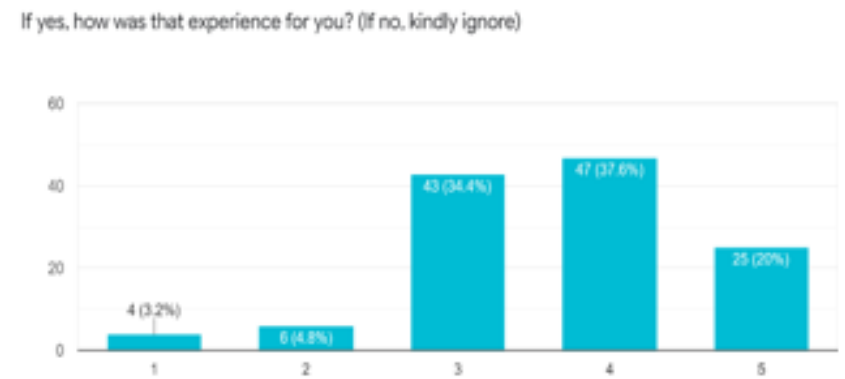

Figure 6: Data for Respondent Profile Source: From Google Survey created by the Authors

\section{Neighbourhood Design}

Various responses have been recorded for the neighbourhood design, where the pattern for the majority can be observed. Though a few people have uncertainties, most people are sure about what they want. Most people prefer having communities with options for physical activities like walking and other natural elements like farms and fields. This also increases the potential for sustainable living within the community. It can also be observed that the people prefer vehicular free environment near the living quarters, but the elderly section has health-related issues which make it difficult to walk a distance to reach the vehicles, due to which they prefer parking's in closer distance (Figure 7). 
Are you comfortable living in a neighborhood with clustered houses?

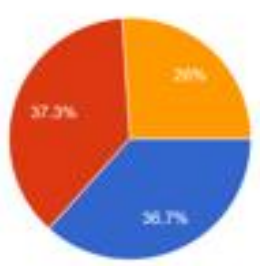

Would you prefer living in a neighborhood with opportunities for wabing and other physical acthinies?
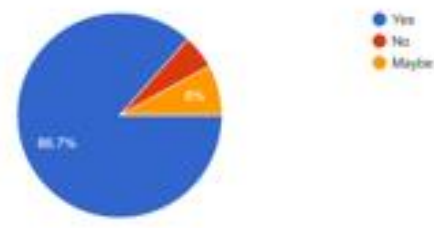

Do rou the the idea of having rour child be able to wabk safoly so their friends house etven without acult supervision?
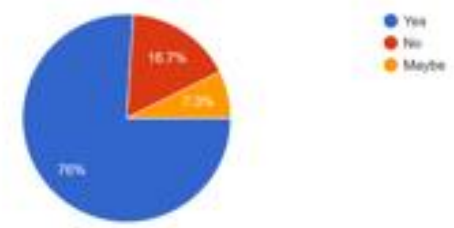

Figure 7: Data for Neighbourhood Design

Source: From Google Survey created by the Authors

\section{Governance Structure}

A variety of opinions can be observed for the governance of the community. Most people prefer the idea of having equal ownership within the community and would also like to be involved in decision making.

The difference in opinion regarding governance shows that the governance structure has to be personalised according to each communities needs and that it will not remain uniform. The responses also show that most people would like to be part of the participatory process of the community (Figure 8).
Would you like to ine in a residence that wal be surrounded by open feldk. farms and tarm irimats
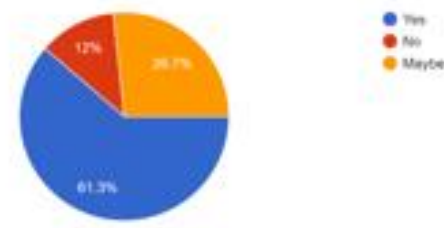

Would you be $\mathrm{CK}$ with a very smat privane parsen, but has an access to a larger shared space?
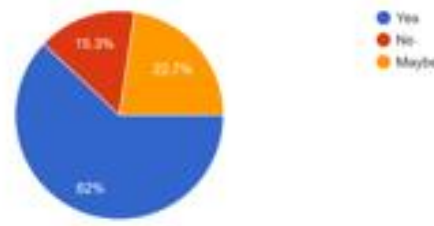

Would you have o problem waking a ditance to the parking area, in order so have a child and pedestrian friendly car-free area?
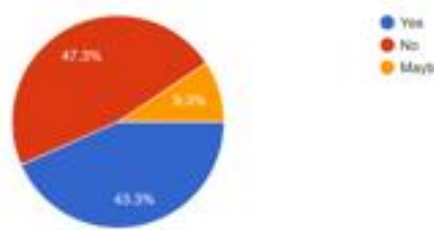

\section{Common Facilities}

Most people agree to the idea of shared living and have a regard to the advantages of such facilities. The majority finds it as an excellent way for socialising and increased level of convenience. Few disadvantages of co-housing as per the users' concerns have also been noted.

Sustainable practices like gardens and farming are options that most people are keen on. The people have recognised a more significant number of benefits than disadvantages for shared living. The most raised concern regarding co-housing is the lack of privacy noted by $74 \%$ of the people, but this can be avoided with the help of proper design and set principles (Figure 9). 


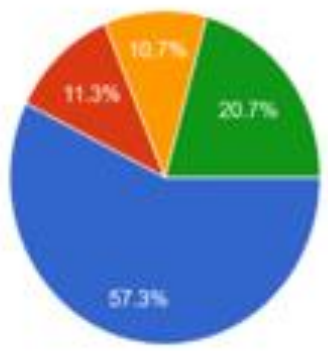

Members share equal ownership

Members pay tent to managemert

Members share different level of

ownership

- Some members own, others rent

Would you like to be involved in establishing and maintaining rules for your neighborhood around such things as pets, clotheslines and parking?
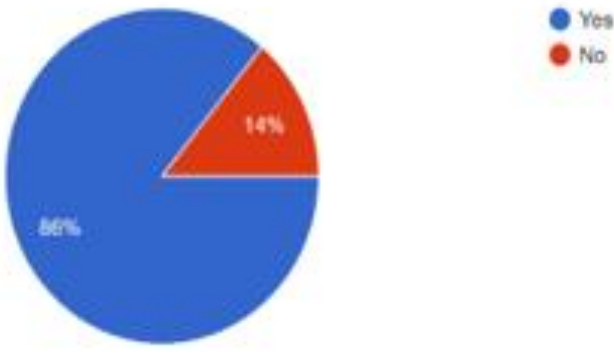

Figure 8: Governance Structure Source: From Google Survey created by the Authors

\section{Private Individual Spaces}

Most people prefer to have housing that can be personalised. They also like clear demarcation between shared and private spaces. Garden, kitchen and common spaces are the spaces that most people are comfortable sharing, whereas the least likely spaces people want to share are their bedrooms and washrooms.

Individualism is a key factor even in co-housing communities. While the community guidelines are set, rules have to be fixed after taking consensus from all the residents. This ensures that every individual takes part in the planning process.

\section{Resident Management}

The people whom you live with is the most crucial aspect of a co-housing community. Though there are differences, a clear majority can be seen in the responses.
From the responses, it can be observed that $36 \%$ of people prefer a small to medium-sized community with 10-25 members having a diverse age group. Families and senior citizens are the most preferred user group. Though most are not comfortable mingling with strangers, they are willing to work together and find solutions with people from different walks of life (Figure 11).

Most people agree upon living among diverse culture and their exposure. Even in terms of clothing, the responses show that the people are comfortable with diversity.

$92 \%$ of the people feel that it is essential to live among people with different cultural backgrounds. This shows the improvement in the mentality of people towards acceptance of different cultures and even gender equality (Figure 12). 
Are you interested in having the option to be involved in farming or community gardens?

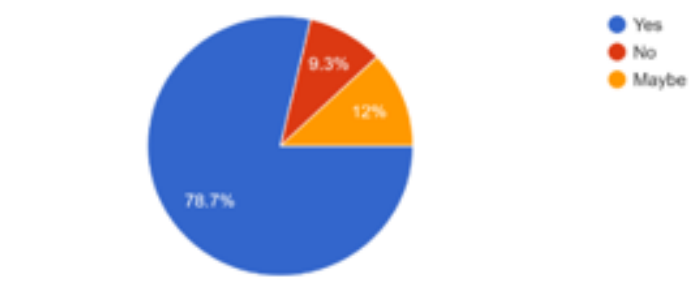

What do you think will be the benefits of living with others?

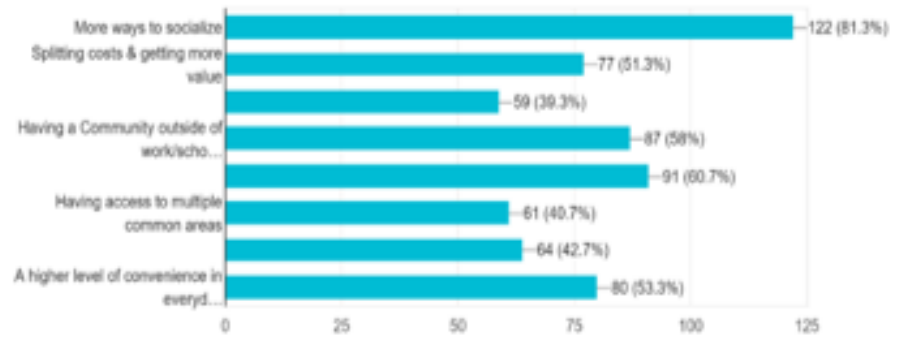

What do you think will be the disadvantages of living with others?

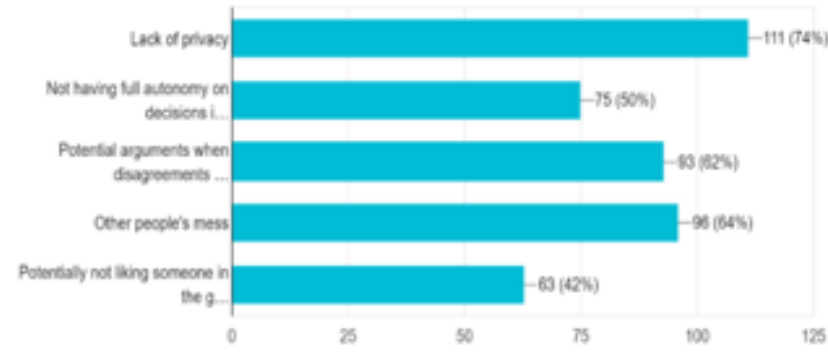

Figure 9: Data for Common Facilities

Source: From Google Survey created by the Authors 
Do you feel comfortable with the idea of living in a small home, that has a common design with less opportunity for personal changes (in term of size or shape)?
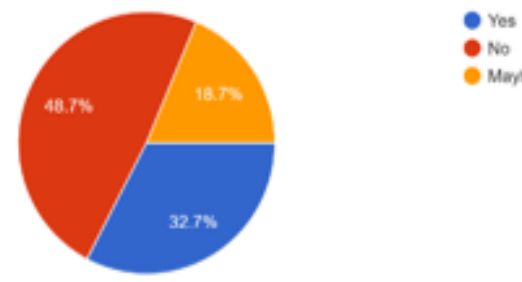

No

Marpe

Which of these items are you comfortable sharing in your home, long-term?

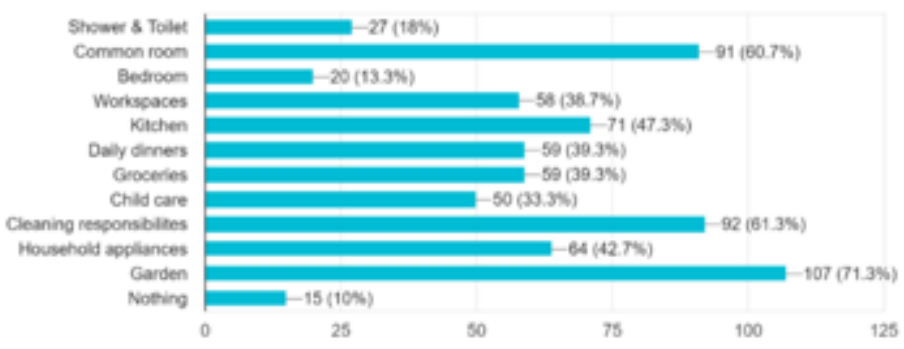

How would you prefer the spaces in the house to be utilized?

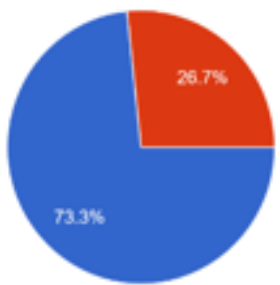

Set phivate spaces and shared spaces with clear boundaries of use

- No clear boundaries. Il can be changed according to wishes

Figure 10: Data for Private Individual Spaces Source: From Google Survey created by the Authors 

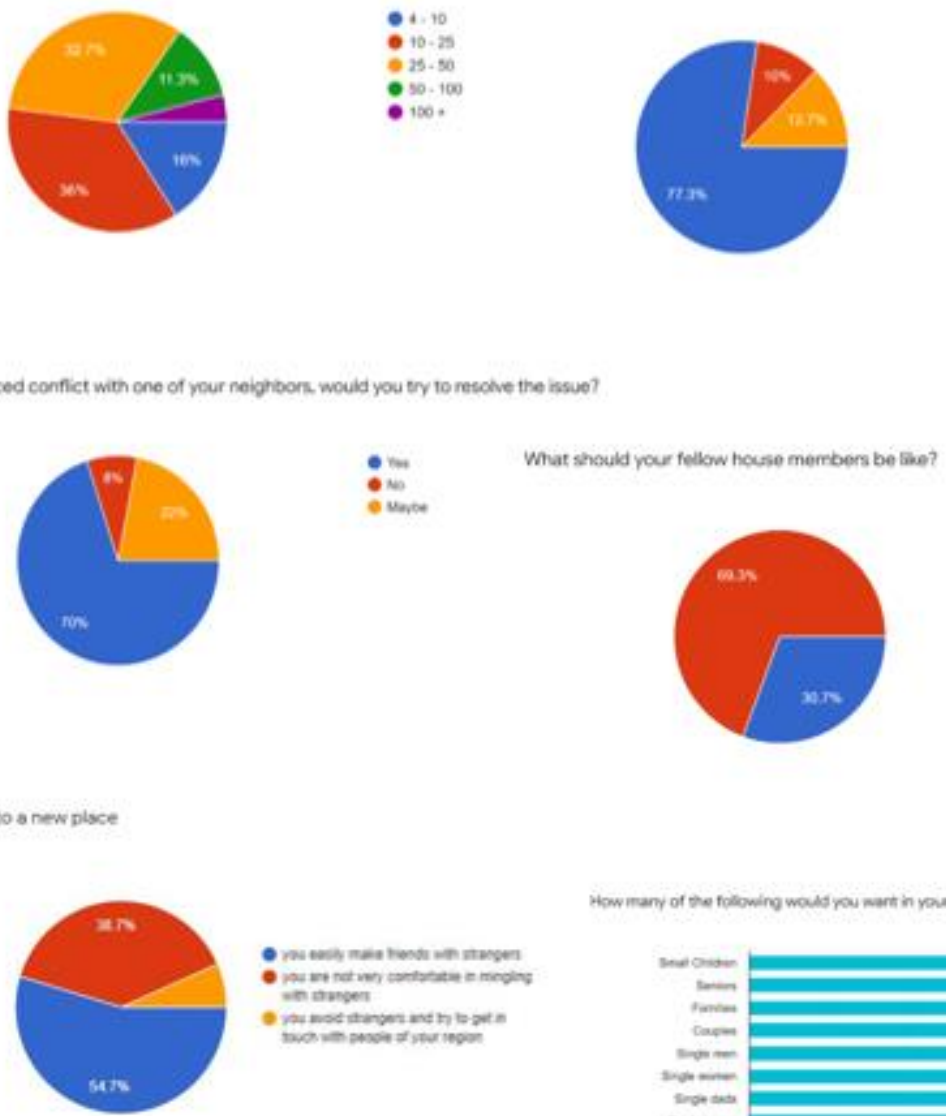

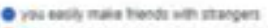

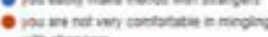

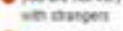

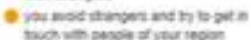

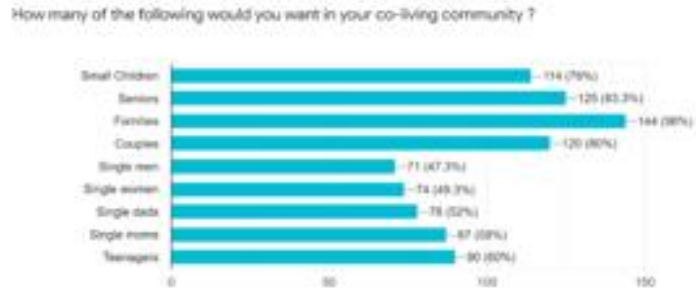

Figure 11: Data for Resident Management Source: From Google Survey created by the Authors Ave you willing to work things through that affect your daily ifo with a group of pecple. many whe have simlar vabues but may not agree on everything?

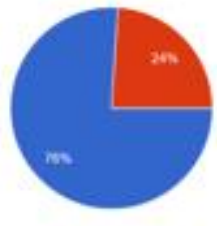

$$
: m
$$

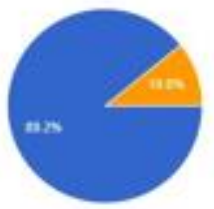

: im

Do you ayree on dividing roles in the conmunity on the bain of gender or chlture?

Do you think it is necessary to the anong diverse culture?
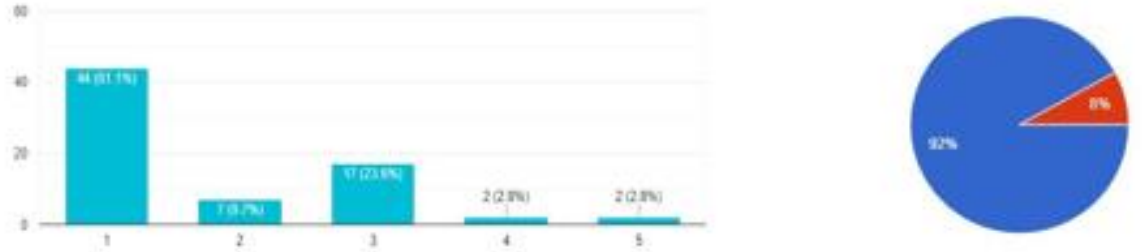


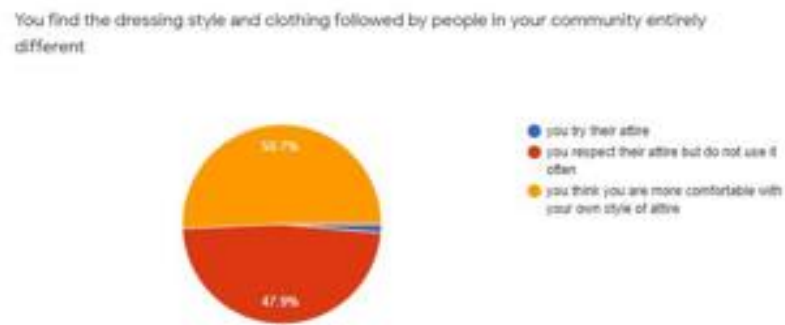

The nerw place hiss a set of rides that you find entirely differenk so your valso syatem

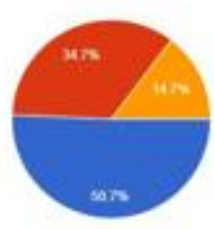

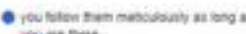

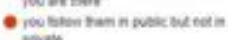

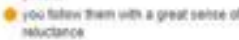

Do rou think a wa bother vou if the people in your community had different dothing and dressing strien?

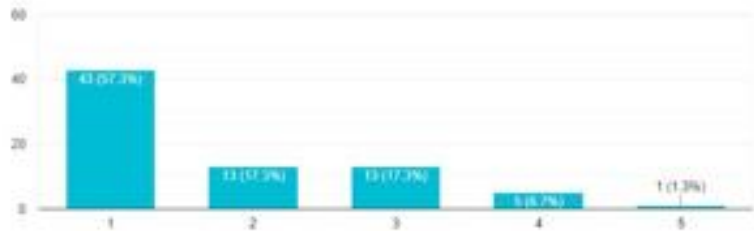

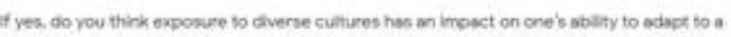
new culture? (fina, whaly lanore)

so inapecen

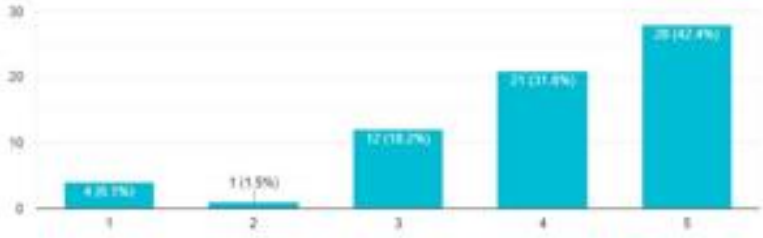

Figure 12: Data for Resident Management (Cultural Management) Source: From Google Survey created by the Authors 


\begin{tabular}{|c|c|c|}
\hline & Parameters & Key Findings \\
\hline \multirow{2}{*}{ 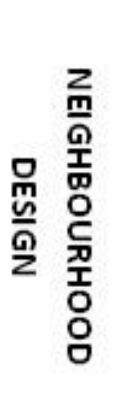 } & Surrounding & $\begin{array}{l}\text { - Communities with options of physical } \\
\text { activities. } \\
\text { - Communities closely related to nature. } \\
\text { - Vehicular free environment. }\end{array}$ \\
\hline & Facilities & $\begin{array}{l}\text { - Close parking provision for elderlies. } \\
\text { - Home based business } \\
\text { - Security and surveillance }\end{array}$ \\
\hline \multirow{2}{*}{ 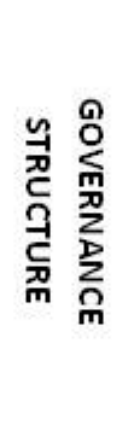 } & Particip atory Process & $\begin{array}{l}\text { - Planning process participation is vital. } \\
\text { - Participation would increase interaction } \\
\text { - Will depend on the scale of the community. }\end{array}$ \\
\hline & Managing Body & $\begin{array}{l}\text { - Will be personalized according to each } \\
\text { community. } \\
\text { - Some scale of involvement expected by most } \\
\text { residents. }\end{array}$ \\
\hline \multirow{2}{*}{ 赑 } & Activities and Management & $\begin{array}{l}\text { - Effective and successful activities are } \\
\text { expected } \\
\text { - Outside areas provide vast opportunities for } \\
\text { social interaction. (Large scale activities) } \\
\end{array}$ \\
\hline & Types & $\begin{array}{l}\text { - Gardening, Farming } \\
\text { - Gym, Club house } \\
\text { - Communal Kitchen }\end{array}$ \\
\hline \multirow{2}{*}{ 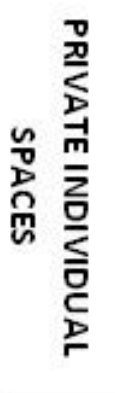 } & Guidelines & $\begin{array}{l}\text { - Clear demarcation of shared and private } \\
\text { spaces. } \\
\text { - Should be pre fixed in the planning stage of } \\
\text { the community. }\end{array}$ \\
\hline & Spaces & $\begin{array}{l}\text { - Not Bedrooms \& Washrooms } \\
\text { - Transition zone between private and public } \\
\text { spaces }\end{array}$ \\
\hline \multirow{2}{*}{ 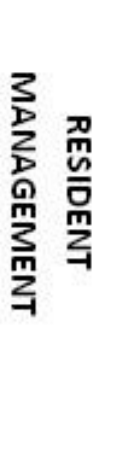 } & Homogeneity \& Size & $\begin{array}{l}\text { - Mixing on neighborhood level, but small } \\
\text { scaled clusters. } \\
\text { - Balance between homogeneity and diversity. } \\
\text { - Small community leads to more bonding. }\end{array}$ \\
\hline & Cultural Aspect & $\begin{array}{l}\text { - Diversity is welcomed but balance is a } \\
\text { necessity. } \\
\text { - Could limit community activities due to } \\
\text { reluctance. }\end{array}$ \\
\hline
\end{tabular}




\section{Reflections on Results}

\section{Key Barriers and Challenges}

\section{Change of Mindset}

It is necessary to encourage a change in the mindset of Indian people towards shared and sustainable living in societies. The true essence of co-housing is still new to Indian citizens. Encouraging collaboration, participation, sharing among individuals and neighbourhoods was deeply embedded in the historic culture of India, but over time urbanisation has diminished it.

\section{Education, Communication and Awareness}

...Co-housing is a completely new way of developing a landscape and anything you do that's new requires a great deal of education - Charles Durrett 2013 (Stratmann et al. 2013,p.36)

Though co-housing is not a new concept or idea as it is intricately connected to the very existence of human beings, over time, it has suffered a loss of relevance. The main challenge is to find ways to revive, reintroduce and raise awareness to communicate the intimate links that co-housing has to our well-being.

\section{Politics}

The politics at city level could act as a barrier for co-housing communities as decisions dictated by them are more often not in the interest of a community or city. Politics often favour individuals than larger communities, hence it has the potential to impact factors like Sustainability etc. High level of social corruption and lack of ethical and moral scruples are also problems that could affect urban development in general and limit the spread of sustainable behaviour (Doucet, 2007).

\section{Parameters for Conceptual Framework}

Co-housing communities can be urban or suburban developments that can be located in various parts of a city. They can vary in size, location, design, type of ownership and priorities. The following characteristics can be incorporated to achieve a successful level in cohousing.

\section{Participatory Process}

The participatory process is expected to occur from the initial phases of development, where the members are expected to engage and negotiate rules and other guidelines for the community. Once the community is established and by involving them in the decision-making process, we create an opportunity for colleagues to share ideas, learn from each other, and work toward a common goal. This helps in ensuring that the community meets the needs of all residents, both collectively and individually.

\section{Demography of Community}

India is a country with a variety of social and cultural differences. Every person will have their own approach to this factor. Some would be well-versed with diversity, but others might prefer people with the same cultural beliefs.

The age group in the community should mainly be mixed, consisting of youngsters, families and senior citizens. This helps in increasing the sense of family and also in supporting one another during essential times. It should be an inclusive neighbourhood, where the residents gain value from each other (Sander, 2005).

As the critical aspect of co-housing is to bring a sense of belonging, there must not be a generalised rule but more personalised guidelines for every community.

\section{Integrated Neighbourhood Design}

The neighbourhood design must help in fostering a sense of family. These designs can be organised according to the following:

- The pedestrian street

- The courtyard

- A hybrid of street and courtyard type

- Single building with an internal atrium that functions as a node of interaction 

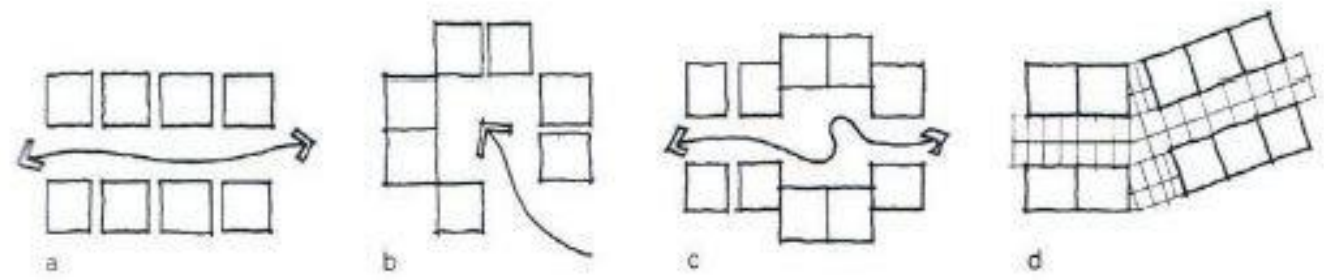

Figure 14: Different Types of Site Plans

Source: McCaant and Durrett 2011, 255

These site plans also include a more efficient design and use of space, so co-housing communities are also a solution for urban environments (Durrett 2009).

\section{Private Homes Supported with Extensive Common Facilities}

Every member and family will hold a private residence and common facilities that need to be shared among the community. The community could have a commune house that constitutes common facilities like a communal kitchen, gym, library etc. There should also be various organised events and outdoor and outdoor activities like celebrations of festivals, community farming, gardening, communal dinners, etc. These have to be decided upon during the participatory stages by all the members and should evolve throughout the community's life. These common facilities are the key factors that constitute the crucial aspect of co-housing for both social and practical reasons.

\section{Governance and Management}

The hierarchical structure will vary from one community to another. This decision will solely rest on the residents who form the community guidelines. The same can be observed from the survey results as well.
The following could be adopted:

- Members share equal ownership

- Members pay rent to the management

- Different level of ownership

- Some members own, others rent.

All the residents must take responsibility for the management of the community. All should participate in the preparation of common meals, meetings and frame guidelines for the community. Every member of the community should autonomously agree on any changes in the decision.

\section{Common Vision towards Sustainability}

Co-housing communities can act as a crucial responder towards sustainable practices. Sustainable practices can be incorporated from the initial stages of design and construction to resident level activities like farming and gardening. This will enhance economic and environmental benefits. The use of renewable energy products like quality sustainable materials, solar panels, efficient heating and cooling systems etc. can support this.

The future of housing and living should be closely linked to sustainability, and it is imperative to incorporate them into day-to-day life. Conceptual Framework for sustainable cohousing practices is demonstrated in Figure 16. 


\section{Who do you think should own the community?}

\section{0 responses}

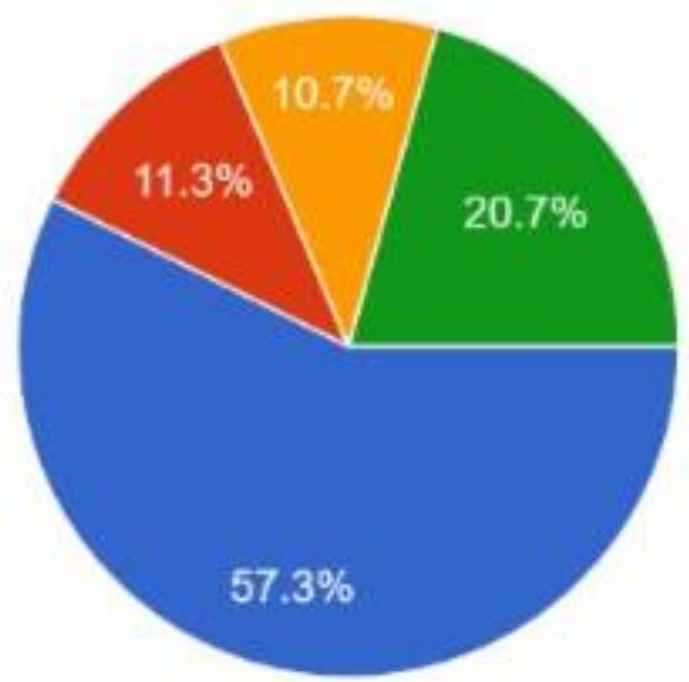

Figure 15: Data for Governance Structure Source: From Google Survey created by the Authors

SOCIAL FACTORS
- Participation in planning
process
- Management \& activities
- Resident Selection
- Diversity

\section{Co-housing Community}

Figure 16: Conceptual Framework for Sustainable Co-housing practices Source: Author 


\begin{tabular}{cll}
\hline Framework Parameters & Recommendations \\
\hline PARTICIPATORY & - Must happen from initial stages \\
PROCESS & - Shery member should be involved \\
\hline COMld continue throughout the like of the community. \\
COMMUNITY
\end{tabular}




\begin{tabular}{|c|c|}
\hline Framework Parameters & Recommendations \\
\hline $\begin{array}{l}\text { PRIVATE HOMES } \\
\text { SUPPORTED WITH } \\
\text { EXTENSIVE COMMON } \\
\text { FACILITIES }\end{array}$ & $\begin{array}{l}\text { - Balance is crucial. } \\
\text { - Every household will have a private residence } \\
\text { - Community house with communal kitchen, gym library etc. } \\
\text { - Variety of organized events and activities. } \\
\text { - Indoor \& outdoor like festival celebration, community farming, } \\
\text { gardening, communal dinners etc. }\end{array}$ \\
\hline $\begin{array}{l}\text { GOVERNANCE \& } \\
\text { MANAGEMENT }\end{array}$ & $\begin{array}{l}\text { - Should not be generalized, will be personalized for each } \\
\text { community. }\end{array}$ \\
\hline $\begin{array}{l}\text { COMMON VISION } \\
\text { TOWARDS } \\
\text { SUSTAINABILITY }\end{array}$ & $\begin{array}{l}\text { - Crucial responders } \\
\text { - Must be incorporated from initial stages of design and } \\
\text { construction like materials renewable energy, solar panels etc. } \\
\text { - Incorporating resident level activities like community farming } \\
\text { gardening etc. }\end{array}$ \\
\hline
\end{tabular}

\section{Figure 17: Summary of Framework \\ Source: Created by the Authors}

\section{Conclusion}

The goal of this research was to study various cohousing communities and their characteristics. The study aimed at realising the importance and the effect it has on its residents. And also, to propose a few guidelines that can be followed by future communities pertaining to India. The following will answer the research questions, thus concluding the study.

Would co-housing aid future generations to improve mental health and well-being in times of crisis?

Through the research, it has become evident that co-housing enhances the well-being of people, not just the youngsters but of every resident in the community. It has been observed that the community begins to act like an extended family helping one another. This belonging is present not just at times of crisis but throughout their daily life.

With the alarming increase of depression, suicide and mental health issues among people, co-housing could become a solution for the same.

Does co-housing offer better opportunities for building smaller and denser, thus tackling the issue of housing in urban cities?

Co-housing does not require large spaces of land; it is very flexible and can be built in dense housing conditions like in the case studies of Share House and Gap House in Japan and South 
Korea, respectively, both of which are countries with similar housing conditions to India.

There are already a numerous hostels and accommodations present in Indian urban cities, but this concept of co-housing is at the nascent stage. Compared to hostel accommodations cohousing offers a communal mind-set where communities strengthen their sense of belonging, making them feel included in some group.

What are the gaps in the present co-housing scenario in India and what is the solution for the same?

The lack of implementation of the true sense of co-housing is the major downfall in the Indian scenario. A true co-housing can only be achieved by following the basic principles and adapting them to Indian scenarios. First and foremost, education and awareness are a must to familiarise people with the accurate idea of cohousing. A change in mindset towards this idea is a necessity.

\section{Limitations}

Few of the factors related to co-housing cannot be generalised in all communities; a level of personalisation is required. The reader should keep in mind that every community will be different from one another as they constitute people with different ideologies.

To find the true success of the selected case studies, one should visit them and communicate with the residents. This is a limitation that this research has. It is solely based on the knowledge openly available.

Further, this study is also unable to encompass a holistic image of the psychological aspects of the community. The interpretations are through the literature study and survey responses.

\section{Recommendation for Future Research}

This study offers the first exploration of cohousing communities in the Indian scenario. It contributes to the existing knowledge by providing a perspective of Indian citizens and their requirements. The results of the same show many similarities with the existing communities with a variation in few aspects like cultural beliefs. These can be explored further. This study can be used to formulate more robust theories and guidelines in terms of the design and management of the community. Further studies can also be done on the incorporation of sustainable practices at various stages in cohousing.

\section{References}

Buffel, T., \& Handler, S. (2019). Age-friendly cities and communities: A global perspective. Policy Press.

Carrere Juli, Reyes Alexia, Oliveras Laura, Fernandez Anna, Peralta Andrés, Novia.m.Ana, Pérez Katherine \& Borrell Carme (2020). The effects of co-housing model on people's health and wellbeing: a scoping review. Public Health Reviews. 41. Article No.22.

https://publichealthreviews.biomedcentral.com/ar ticles/10.1186/s40985-020-00138-

1\#: :text=The\%20existing\%20literature\%20on\%20 co-housing,between $\% 20$.

Chris Scotthanson \& Kelly Scotthanson (2005). Building a place for community. The Cohousing Handbook. Revised Edition. New Society Publishers.

Crerar, P. (2017, December 20). 'Tens of thousands' of people living in beds in sheds across London. London news | London Evening standard.

https://www.standard.co.uk/news/politics/ten s-of-thousands-of-people-living-in-beds-insheds-across-the-capital-report-showsa3723786.html

Cummings, S., \& Kropf, N. P. (2019). Living and learning-The senior Co-housing experience. SpringerBriefs in Aging, 71-

79. https://doi.org/10.1007/978-3-030-253622_9

Doucet, Clive (2007). Urban Meltdown. Cities, Climate Change and Politics as Usual. New Society Publisher.

Holtzman, Gilo (2010). Introduction to Cohousing and the Australian context. https://issuu.com/polosnow/docs/introductionto-co-housing-and-the-a 
Jarvis, Helen (2015). Towards a deeper understanding of the social architecture of Cohousing: Evidence from the UK, USA and Australia. Urban Research \& Practice, 8(1), 93105. https://doi.org/10.1080/17535069.2015.1 011429

Jarvis, Helen(2011). Saving Space, Sharing Time: Integrated Infrastructures of Daily Life in Cohousing. Environment and Planning. 43(3), https://doi.org/10.1068/a43296

Kim, Grace (2012). Co-housing Common House Design. Schemata Workshop.

https://issuu.com/schemataworkshop/docs/cohousing_common_house_design

Little, William \& McGivern, Ron (2012). Introduction to Sociology - 1st Canadian Edition. https://opentextbc.ca/introductiontosociology/ch apter/chapter14-marriage-and-family.

Mary, Claus (n.d. ). 5 Reasons To Consider Joining A Co-housing Community, The Good Trade.

https://www.thegoodtrade.com/features/5reasons-to-consider-joining-a-co-housingcommunity.

Max-Neef, M. (1991). Human Scale Development: conception, application and further reflections. The Apex Press.

http://www.areanet.org/fileadmin/user_uploa d/papers/Maxneef_Human_Scale_developmen t.pdf

McCamant, K., \& Durrett, C. (2011). Creating Co-housing: Building sustainable communities. New Society Publishers

McCamant, Kathryn., \& Durrett, Charles, Hertzman, Ellen (1994). Co-housing: A contemporary approach to housing ourselves.Ten speed Press.

Meyer, Keyer (2018). Neighbors helping neighbors: Co-housing options for older adults to age in place. Master of Social Work Clinical Research Papers.

https://sophia.stkate.edu/msw_papers/.

No author (nd). Max -Need on Human needs and Human scale development.

https://www.rainforestinfo.org.au/background/m axneef.html.
Pearson, L. F. (1988). Communal living today. The Architectural and Social History of Cooperative Living, 202-

219. https://doi.org/10.1007/978-1-349-

19122-2_11

Prentice, D., \& Scutella, R. (2019). What are the impacts of living in social housing? New evidence from Australia. Housing Studies, 35(4), 612-

647. https://doi.org/10.1080/02673037.2019.1 621995

Sander, R. (2005). Preventing social isolation and loneliness among older people: A systematic review of health promotion interventions. Nursing Older People, 17(1), 4040. https://doi.org/10.7748/nop.17.1.40.s11

Stratmann, Judith., Ferreiro,Weiss Laura., \& Narayan Rumy (2013). Towards Sustainability Analysis of Collaborative Behaviour in Urban Co-housing. Thesis submitted for completion of Master's in Strategic Leadership towards Sustainability, Blekinge Institute of Technology, Karlskrona, Sweden.

Sundar, Nandhini (2018). Heard of Co-living spaces?. Homes and Gardens - The Hindu. https://www.thehindu.com/life-andstyle/homes-and-gardens/heard-of-co-livingspaces/article24410306.ece.

The Guardian (2019, September, 03). 'Coliving': the end of urban loneliness - or cynical corporate dormitories?.https://www.theguardian.com/ci ties/2019/sep/03/co-living-the-end-of-urbanloneliness-or-cynical-corporate-dormitories

White, N. J., \& Loper, C. (2015). Co-housing: An idea for the modern age. SSRN.

https://doi.org/10.2139/ssrn.2559820.

\section{Conflict of Interest}

The authors have no conflicts of interest to declare. All co-authors have seen and agree with the contents of the manuscript, and there is no financial interest to report. We certify that the submission is original work and is not under review at any other publication. 


\section{Author Contribution Statement}

Nandana

Madathil

Thankamoniyan:

conceptualisation, methodology, and software contribution, curation of data, developing the first draft, conducting empirical research, analysing and visualising data; developing the final draft alongside editing, reproduction of figures.

Dr. Sharmila Jagadisan: conceptualisation, methodology, guidance and supervision, collecting references, validating the data, rewriting and modifying the final draft, reviewing the final draft and final editing. 